\title{
Survey of Hypertension in Dhaka, Bangladesh: Changing Prescribing Patterns
}

\author{
Md Sazzad Hossain*, Nizam Uddin, AFM Mahmudul Islam, Raziul Hassan \\ Akash, Md Mahadi Hasan, Tanay Kumar Saha, Md Monir Hossain, Mohammad \\ Asikur Rahman and Md Sohel Rana \\ Department of Pharmacy, Jahangirnagar University, Savar, Dhaka-1342, Bangladesh
}

*For correspondence: Email: sazzad.phrm@gmail.com; Tel: +8801937045322

Received: 20 September 2014

Revised accepted: 10 January 2015

\begin{abstract}
Purpose: To assess changes in the prescribing pattern of antihypertensive drugs and lifestyle factors associated with hypertensive patients in Dhaka, Bangladesh.

Methods: A cross-sectional study was conducted among 50 hypertensive patients in various heart disease hospitals and the consulting rooms of 10 cardiologists in the city of Dhaka to determine changes in prescribing patterns of antihypertensive drugs. Respondents were distributed more or less equally between males and the females.

Results: Female patients aged 30 to 40 years (8\%) as well as male patients aged 50 to 60 years (54 $\%)$ and 60 to 70 years (12\%) were prone to hypertension. However, patients of both sexes whose age ranged from 40 to 50 (40\%) and 50 to 60 (36\%) were more prone to hypertension. It was observed that $46 \%$ of the patients were overweight. A majority of the patients had diabetes with hypertension (28\%). Moreover, most of the patients (80\%) did not indulge in any physical exercise and were non-smokers but had a family history of hypertension. Combined antihypertensive drugs, especially thiazide diuretics with angiotensin II receptor blockers, calcium antagonists, and angiotensin-converting enzyme (ACE) inhibitors were the first choice of drugs by physicians. The prescribing rate of $\beta$-blockers (28.36\%) and combined antihypertensive preparations (40\%) was higher than that of older antihypertensives, viz loop diuretics, propranolol and enalapril.

Conclusion: Combination therapy is favored by all doctors who compared with the past prescribing practice of a single medication for hypertension.
\end{abstract}

Keywords: Hypertension, Prescribing pattern, Antihypertensive drugs, Lifestyle factors, Family history

Tropical Journal of Pharmaceutical Research is indexed by Science Citation Index (SciSearch), Scopus, International Pharmaceutical Abstract, Chemical Abstracts, Embase, Index Copernicus, EBSCO, African Index Medicus, JournalSeek, Journal Citation Reports/Science Edition, Directory of Open Access Journals (DOAJ), African Journal Online, Bioline International, Open-J-Gate and Pharmacy Abstracts

\section{INTRODUCTION}

Blood pressure (BP) is considered as the most effective measurable marker of the potential level of cardiovascular risk [1], and continuous systolic/diastolic blood pressure higher than accepted normal values is designated as hypertension [2]. Hypertension is currently considered the second most important preventable risk factor for premature death $[3,4]$.
It is the complex etiologic disease that affects 972 million people around the world [5].

In 2003 American Heart Association (AHA) classified hypertension and defined systolic and diastolic pressure into distinctive range [6]. Mild to moderate essential hypertension is usually asymptomatic [7]. Secondary hypertension, also called high blood pressure, may be caused by another medical condition or medication [8]. It is 
the condition in which blood pressure increases to an extent where clinical benefit is obtained from blood pressure lowering [9]. Persistent hypertension is one of the prime reasons for several types of cardiovascular diseases, such as myocardial infarction, stroke, and arterial aneurysm as well as chronic kidney dysfunction [10] Other than these, it may cause vision disorders, confusion, headache, drowsiness, chest pain, nausea, and vomiting which are collectively referred to as hypertensive encephalopathy [11].

Hypertension may co-exist with diabetes in a number of populations [12]. It is the most common medical problem during pregnancy [13] and a major cause of perinatal and maternal morbidity and mortality [14], developing preeclampsia or an adverse pregnancy outcome [15]. There is a close relation between hypertension and Body mass index (BMI) [16]. $\mathrm{BMI}$ is categorized according to the recommendations of the World Health Organization (WHO) [17].

The objective of the present study was to determine the change in prescribing patterns of antihypertensive drug in time and to evaluate lifestyle factors associated with hypertensive patients.

\section{METHODS}

A cross-sectional study was conducted in 4 cardiac hospitals in the city of Dhaka, Bangladesh, including National Institute of Cardio-Vascular Disease Hospital (NICVD), National Heart Foundation, Jahangirnagar University Medical Center and the local clinics to determine the prescribing patterns of antihypertensive drugs with the informed consent of the participant patients. This survey was conducted in the following two ways namely survey of (i) 50 hypertensive patients, and (ii) cardiologists at their consulting room.

\section{Survey of patients}

Initially, the patients in the hospitals who had hypertension were selected at random. It was possible to select the patients by observing the levels of blood pressure and antihypertensive drugs that were prescribed in their prescriptions. They were asked questions about their lifestyle and the drugs they were taking. The information was collected from each subject through a validated questionnaire which contained questions on age, sex, height, weight, diseases, regular physical exercise, history of diabetes, smoking habit, family history of hypertension, past history of blood pressure and hypertension, hard work, regularity in taking medicine and the changed pattern of prescribed antihypertensive preparations.

\section{Survey of physicians}

Only 10 cardiologists, medicine specialists, Indoor and outdoor cardiologists were included in this survey.

A prepared list of antihypertensive drugs was supplied to each physician. Each physician marked the name of the drugs that he/she previously had prescribed and is now prescribing. This was done to determine the change of prescribing patterns of antihypertensive drugs with the change of time.

\section{Inclusion and exclusion criteria}

Patients in all age groups who came to the physicians for the treatment of hypertension were included. However, patients with coronary heart disease, cerebrovascular disease, peripheral arterial disease, rheumatic heart disease and congenital heart disease, were excluded [18]. Moreover, the patients with neurological disorder were also excluded. The patients, especially the females who showed negligence to show prescriptions to others were not included in the survey.

\section{Data collection and processing}

The patients coming out from the consulting rooms and hospitals were screened based on the inclusion and exclusion criteria. Those who were included in our survey filled out the questionnaires and the data collected from the questionnaires filled up by the patients were used for further analysis.

\section{Statistical analysis}

All data were analyzed using SPSS version 16 and JMP Statistical Software version 7 (SAS Institute, USA). Analysis of previous and current medications used by patients or suggested by physicians was done by frequency distribution using Microsoft Excel 2007. Besides, Chi square test was performed for demographic profile and frequency distribution of diseases. Mann-Whitney $U$ statistical analysis was carried out on data from previous and present drugs taken by patients and prescribed by physicians. Moreover, linear regression analysis was performed to determine the relationship between systolic and 
diastolic blood pressure. $P<0.05$ was considered statistically significant.

\section{RESULTS}

Age- and sex-specific information of hypertensive patients

Information obtained from hypertensive patients according to age, sex and BMI is shown in Table 1. Among the patients, 26 were males (52\%) and $24(48 \%)$ were females.

Table 1: Frequency distribution of hypertensive patient according to age, sex and BMl

\begin{tabular}{lccc}
\hline \multirow{2}{*}{ Variable } & \multicolumn{2}{c}{ Patient } & \multirow{2}{*}{ Total } \\
\cline { 2 - 3 } & Male & Female & \\
\hline Age (years) & 0 & 1 & 1 \\
$<20$ & 0 & 2 & 2 \\
$20-30$ & 1 & 1 & 2 \\
$30-40$ & 6 & 14 & 20 \\
$40-50$ & 14 & 4 & 18 \\
$50-60$ & 3 & 1 & 4 \\
$60-70$ & 2 & 1 & 3 \\
$>70$ & $\mathbf{2 6}$ & $\mathbf{2 4}$ & $\mathbf{5 0}$ \\
Total & 0 & 1 & 1 \\
BMI & 15 & 10 & 25 \\
$<18.5 \mathrm{~kg} \mathrm{~m}^{-2}$ & 11 & 12 & 23 \\
$18.5-24.9 \mathrm{~kg} \mathrm{~m}^{-2}$ & 0 & 1 & 1 \\
$25.0-29.9 \mathrm{~kg} \mathrm{~m}^{-2}$ & 0 & 0 & 0 \\
$30.0-39.9 \mathrm{~kg} \mathrm{~m}^{-2}$ & 0 & $\mathbf{2 4}$ & $\mathbf{5 0}$ \\
$>40 \mathrm{~kg} \mathrm{~m}^{-2}$ & $\mathbf{2 6}$ &
\end{tabular}

For age (all patients), Chi square value was 56.120 ( $p$ $<0.001)$ and 42.480 for BMI $(p<0.001)$

The frequency table shows the precise frequencies for each category. Only one patient was found in underweight range $\left(<18.5 \mathrm{~kg} \mathrm{~m}^{-2}\right)$ and it is only $2 \%$ of the total patients. 25 patients were found in normal weight $(50 \%)$ range (18.5 $-24.9 \mathrm{~kg} \mathrm{~m}^{-2}$ ) and 23 were found in overweight $(46 \%)$ range $\left(25.0-29.9 \mathrm{~kg} \mathrm{~m}^{-2}\right)$. One patient was found in Grade - 2 overweight / obesity (2 $\%)$ range $\left(30.0-39.9 \mathrm{~kg} \mathrm{~m}^{-2}\right)$. No patient was found in morbidly obese ( $>40 \mathrm{~kg} \mathrm{~m}^{-2}$ ) range. Moreover, chi square test showed significant variation in both age and BMl categories $(p<$ 0.001).

\section{Frequency distribution of disease except or within hypertension}

Four of the patients had stroke, 5 had lung disease, 7 had heart attack, 19 had diabetes, 3 had kidney disease, 5 had chest pain, 1 had ischemic heart disease (IHD) and 17 had other diseases accompanied with hypertension. Chi square test was performed to analyze the data set. Here chi square value is $41.06(p<0.001)$.

\section{Patients' lifestyle factor}

We asked the patients about their lifestyle factor in the form of a questionnaire which contained some information about their lifestyles such as regularity in their physical exercise, smoking habit, family history of hypertension, regular checking of blood pressure, habit of hard work, and regularity in taking their medicine and so on. Those who gave affirmative reply were included in the 'Yes' category and those who gave negative reply were included in the 'No' category. For above 6 factors, chi square values with $p$ values were found as $18.00(p<0.001), 8.00$ ( $p$ $<0.01), 23.12(p<0.001),<0.001(p>0.05)$, $13.52(p<0.001)$, and $46.080(p<0.001)$ respectively."

Chi square test results for patients' lifestyle indicate that, except for regularity in checking blood pressure, all other factors significantly affected patients' lifestyle. The highest variation was recorded for the last factor, i.e., regularity in taking prescribed medicines (Chi square, 46.08) suggests that this factor greatly affected the normal lifestyle of hypertensive patients.

\section{Relationship between systolic and diastolic blood pressure}

Bivariate analysis and age specific distribution of mean systolic-diastolic blood pressure of both the male and the female patients are shown in Figure 1 and Table 2, respectively.

From Figure 1 ( $A$ and $B$ ) it was found that a significant relationship exists between systolic and diastolic blood pressure for women $(p<$ $0.0001, R$ square value of 0.68 ) but not for man $(p>0.05, \mathrm{R}$ square value of 0.15$)$. From the Table 2 we can see that the male patients whose age range from $50-60$ years $(n=14)$ are most prone to hypertension having $146.7(\mathrm{mmHg})$ mean systolic blood pressure and $96.3(\mathrm{mmHg})$ mean diastolic blood pressure which are higher than all age ranges of the male patients. Females whose ages range from $40-50(n=14)$ are most prone to hypertension having 141.1 $(\mathrm{mmHg})$ mean systolic blood pressure and 91.8 $(\mathrm{mmHg})$ mean diastolic blood pressure.

\section{Antihypertensive drugs taken by patients}

We used the information about the drugs that were taken previously and are now taken by the patients, given in Table 3 . 

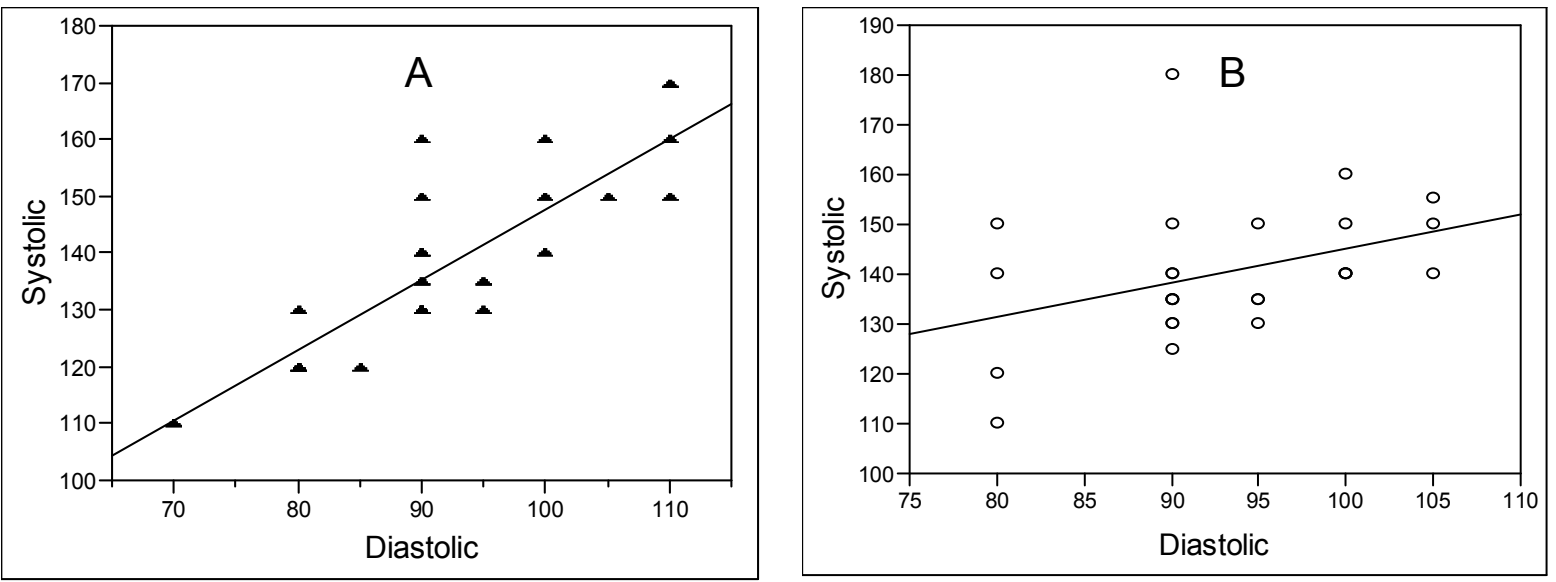

Figure 1: A) Bivariate fit of systolic by diastolic blood pressure for female patients $(\Delta)$. The equation is: Systolic = $24.311352+1.2337229 \times$ Diastolic. B) Bivariate fit of systolic by diastolic blood pressure for the male patients (०). The equation is: Systolic $=75.840475+0.6928148 \times$ Diastolic

Table 2: Age- and sex-specific distribution of mean systolic and diastolic pressure among the sample population $($ mean \pm SD)

\begin{tabular}{lcccc}
\hline $\begin{array}{l}\text { Age range } \\
\text { (years) }\end{array}$ & $\begin{array}{c}\text { Male systolic } \\
(\mathbf{m m H g})\end{array}$ & $\begin{array}{c}\text { Male diastolic } \\
(\mathbf{m m H})\end{array}$ & $\begin{array}{c}\text { Female systolic } \\
(\mathbf{m m H g})\end{array}$ & $\begin{array}{c}\text { Female diastolic } \\
(\mathbf{m m H g})\end{array}$ \\
\hline$<20$ & 0 & 0 & $130.0 \pm 0.00$ & $95.0 \pm 0.00$ \\
$20-30$ & 0 & 0 & $137.5 \pm 3.54$ & $97.5 \pm 3.53$ \\
$30-40$ & $115.0 \pm 7.07$ & $80.0 \pm 0.00$ & $160.0 \pm 0.00$ & $110.0 \pm 0.00$ \\
$40-50$ & $135.0 \pm 7.56$ & $94.4 \pm 5.63$ & $141.1 \pm 16.66$ & $91.8 \pm 9.92$ \\
$50-60$ & $146.7 \pm 13.54$ & $96.3 \pm 6.08$ & $127.5 \pm 15.00$ & $88.8 \pm 14.36$ \\
$60-70$ & $142.5 \pm 10.61$ & $92.5 \pm 3.54$ & $130.0 \pm 0.00$ & $80 \pm 0.00$ \\
$>70$ & $145.0 \pm 7.07$ & $80.0 \pm 0.00$ & $130.0 \pm 0.00$ & $90 \pm 0.00$
\end{tabular}

Table 3: Assessment of previous and present drugs taken by patients

\begin{tabular}{|c|c|c|c|c|}
\hline \multirow[b]{2}{*}{ Drug } & \multicolumn{2}{|c|}{ Previous drugs } & \multicolumn{2}{|c|}{ Present drugs } \\
\hline & $\begin{array}{c}\text { No. of times } \\
\text { prescribed }\end{array}$ & $\%$ & $\begin{array}{l}\text { No. of times } \\
\text { prescribed }\end{array}$ & $\%$ \\
\hline Indapamide & 1 & 2.38 & 1 & 1.49 \\
\hline Furosemide, Torasemide & & 0 & 1 & 1.49 \\
\hline Furosemide + Spironolactone & 2 & 4.76 & 3 & 4.48 \\
\hline Atenolol & 24 & 57.14 & 5 & 7.46 \\
\hline Propranolol & & 0 & 1 & 1.49 \\
\hline Metoprolol & & 0 & 9 & 13.43 \\
\hline Carvedilol & & 0 & 4 & 5.97 \\
\hline Nifedipine & 6 & 14.29 & 2 & 2.99 \\
\hline Amlodipine & 5 & 11.9 & 4 & 5.97 \\
\hline Enalapril & 1 & 2.38 & & 0 \\
\hline Ramipril & & & 6 & 8.96 \\
\hline Losartan K & 1 & 2.38 & 4 & 5.97 \\
\hline Atenolol + Amlodipine & 2 & 4.76 & 15 & 22.39 \\
\hline Indapamide + Perindopril & & & 1 & 1.49 \\
\hline Losartan + Hydrochlorothiazide & & & 11 & 16.42 \\
\hline Total & $(10.62) 42^{a}$ & $100 \%$ & $(12) 67^{a}$ & $100 \%$ \\
\hline
\end{tabular}

Note: Other antihypertensive drugs were not found in any prescription. That is why they are excluded. Values sharing same superscripts are not significantly different from each either $(p>0.05)$. Mann-Whitney $U$ statistics value found was of 49.00. In the last row the data are presented as (mean rank) total times of the prescribed drugs 
Table 4: Assessment of the previous and the present drugs prescribed by the physicians

\begin{tabular}{|c|c|c|c|c|}
\hline \multirow[b]{2}{*}{ Generic name } & \multicolumn{2}{|c|}{ Previous drugs } & \multicolumn{2}{|c|}{ Present drugs } \\
\hline & $\begin{array}{l}\text { No. of times } \\
\text { prescribed }\end{array}$ & $\%$ & $\begin{array}{l}\text { No. of times } \\
\text { prescribed }\end{array}$ & $\%$ \\
\hline Thiazides: Bendroflumethiazide & 2 & 3.51 & 1 & 1.21 \\
\hline Hydrochlorothiazides: Indapamide & & 0 & 4 & 4.82 \\
\hline Loops: Furosemide, Torasemide & 2 & 3.51 & & 0 \\
\hline Furosemide + Spironolactone & 3 & 5.26 & 3 & 3.61 \\
\hline Thiazides + Amiloride & 3 & 5.26 & & 0 \\
\hline Atenolol & 8 & 14.04 & 7 & 8.43 \\
\hline Propranolol & 4 & 7.02 & & 0 \\
\hline Metoprolol & 1 & 1.75 & 6 & 7.23 \\
\hline Bisoprolol & 2 & 3.51 & 4 & 4.82 \\
\hline Carvedilol & & 0 & 5 & 6.02 \\
\hline Prazosin & & 0 & 1 & 1.21 \\
\hline Nifedipine & 6 & 10.53 & 1 & 1.21 \\
\hline Amlodipine & 8 & 14.04 & 8 & 9.64 \\
\hline Verapamil & & 0 & 3 & 3.61 \\
\hline Diltiazem & & 0 & 4 & 4.82 \\
\hline Enalapril & 6 & 10.53 & & 0 \\
\hline Perindopril & & 0 & 1 & 1.21 \\
\hline Ramipril & & 0 & 9 & 10.84 \\
\hline Losartan & 6 & 10.53 & 4 & 4.82 \\
\hline Valsartan & & 0 & 2 & 2.41 \\
\hline Irbesartan & & 0 & 4 & 4.82 \\
\hline Minoxidil & 1 & 1.75 & & 0 \\
\hline Atenolol + Amlodipine & 2 & 3.51 & 6 & 7.23 \\
\hline Atenolol + Chlorothiazide & 2 & 3.51 & & 0 \\
\hline Benazepril + Amlodipine & & 0 & 2 & 2.41 \\
\hline Indapamide + Perindopril & & 0 & 1 & 1.21 \\
\hline Losartan + Hydrochlorothiazides & 1 & 1.75 & 7 & 8.43 \\
\hline Total & $(18) 57^{a}$ & $100 \%$ & $(19.76) 83^{a}$ & $100 \%$ \\
\hline
\end{tabular}

Note: Other antihypertensive drugs were not prescribed by any physicians. That is why they are excluded. Values sharing same superscripts are not significantly different from each either $(p>0.05)$. Mann-Whitney $U$ statistics value was 152.00. In the last row the data are presented as total times (mean rank) prescribed

\section{Antihypertensive drugs prescribed physicians}

We used the information of drugs that were prescribed previously and are prescribed now by the physicians in Table 4 which shows the percentage of the antihypertensive drugs prescribed previously and presently.

In the frequency table (Table 3), previously taken drug column shows the precise frequencies for each category. Mann-Whitney $U$ statistics found no significant difference in total times of the prescribed drugs in two conditions $(p>0.05)$. The frequency column reports that 24 of our prescriptions contained atenolol which is equivalent to $57 \%$ of the total number of prescriptions. Again, the frequency column reports that 6 of our prescriptions (14\%) contained nifedipine and 5 of our prescriptions (12\%) contained amlodipine. The loop diuretics (i.e., furosemide, torasemide), propranolol, metoprolol, carvedilol, ramipril, indapamide + perindopril, losartan + hydrochlorothiazides were not previously taken by any patient. We used the information of the present drugs that are being taken by patients in Table 3 which shows the percentage of antihypertensive drugs that are taken presently. In the frequency table, the column of the present pattern of antihypertensive drugs shows the precise frequencies for each category. The frequency column reports that 15 of our prescriptions contained atenolol + amlodipine. This is equivalent to $22 \%$ of the total number of prescriptions. Again the frequency column reports that $9(13 \%)$ of our prescriptions contained the metoprolol, 11 (16\%) of the prescriptions contained losartan + hydrochlorothiazides, and $6 \quad(9 \%)$ of the prescriptions contained ramipril. But now enalapril is not taken by any patient that was previously taken. In the frequency table (Table: 3) previously prescribed drugs column shows the precise frequencies for each category.

Mann-Whitney $U$ statistics showed that total times of the prescribed drugs did not differ significantly in two conditions $(p>0.05)$. The frequency column reports that both atenolol and amlodipine were prescribed by physicians for 8 
times. This is equivalent to $14 \%$ of the total number of prescriptions. But the physicians prescribed nifedipine, enalapril and losartan for 6 times. This is equivalent to $11 \%$ of the total number of prescriptions. But other antihypertensive drugs except those in the above mentioned table were not prescribed by any physicians. We used the information of the present drugs that are being prescribed by the physicians in the Table 3 which show the percentage of antihypertensive drugs that are prescribed presently. In the frequency table 4 , the present pattern of antihypertensive drug column shows the precise frequencies for each category. The frequency column reports that ramipril is being prescribed by the physicians for 9 times. This is equivalent to $11 \%$ of the total number of prescriptions. Again, the frequency column reports that amlodipine is currently being prescribed by the physicians for 8 times $(10 \%)$, both losartan + hydrochlorothiazides and atenolol are being prescribed by the physicians for 7 times $(8 \%)$ and both atenolol + amlodipine and metoprolol are being prescribed by the physicians for 6 times $(7 \%)$. But other antihypertensive drugs are not being prescribed by any physicians.

\section{DISCUSSION}

Changing dietary and lifestyle patterns can control blood pressure and reduce the risk factors associated with cardiovascular diseases, i.e., ischemic heart disease, stroke; although drug therapy may prove the necessities in patients for whom lifestyle pattern changes have proved to be ineffective or insufficient [19]. The age of the majority of our selected patients ranged from 40 to $60(76 \%)$. The average life expectancy of Bangladeshi people is almost 70 years and majority of its population has hypertension after 40 years. The possible reasons for early occurrence of hypertension in these people may be inadequate dietary intake, lack of consciousness about the root cause of hypertension, working in stressed condition, anxiety, excess salt \& fast-food consumption. Lifestyle changes may help to control blood pressure but the goal of treatment is to reduce blood pressure so that the patients have a low risk of complications [20]. In order to prevent hypertension physicians put emphasis on the change of the lifestyle of the people. But the majority of the people of Bangladesh try to control this disease by reducing their smoking habit, eating balanced diet and taking medicine regularly. It may be mentioned here that they do not take physical exercise regularly in order to prevent this disease. Moreover, they eat excess salt based diet which causes blood pressure. It may also be mentioned here that as their lives are full of anxieties, they become easily attacked with this disease. To the best of our knowledge, this may be the first study to evaluate the prescribing patterns which change from a single generic to the combined antihypertensive preparations and even newer generics. The prevalence of hypertension is high and the prescriptions containing combined antihypertensive preparations are increasing day by day. The increasing use of combined antihypertensive preparations may be due to increase in health-related complications as well as other factors associated with hypertension among the patients. As a result, we noticed increased use of combination therapies and newer generics which may ultimately increase health-related costs in developing countries such as Bangladesh. The exact cause of increased health-related complications are unknown. Further studies may be required to determine this as well as probable ways to minimize such complications.

\section{Limitations of the study}

The sample size of this survey was small. It would have been better if a sufficient number of patients and physicians were included in the survey. Also, since this survey was carried out only in an urban area, the findings would not reflect the overall situation of hypertension throughout Bangladesh.

\section{CONCLUSION}

Findings from this study indicate that combined antihypertensive preparations are being used more widely than single generics. This has definite implications for the patient and the healthcare system in terms of health related cost. In Bangladesh, physicians are now more likely to prescribe combined antihypertensive drugs than single drugs for hypertension. Atenolol with amlodipine preparation was the most frequently prescribed combination. Losartan and olmesartan with hydrochlorothiazides was another frequently used combination. Further studies are required to determine the factors responsible for the change in prescribing pattern of antihypertensive drugs.

\section{ACKNOWLEDGEMENT}

The authors are thankful to Professor Abdullah Faruque, Department of Pharmacy, Jahangirnagar University, for providing logistic support and encouragement during this survey. 
The authors are also thankful to Professor Shahab Uddin, former Principal, Noakhali Government Women's College, Bangladesh for improving the language of this paper.

\section{REFERENCES}

1. Williams CL, Hayman LL, Daniels SR, Robinson TN, Steinberger J, Paridon S, Bazzarre T. Cardiovascular health in childhood: A statement for health professionals from the Committee on Atherosclerosis, Hypertension and Obesity in the Young (AHOY) of the Council on Cardiovascular Disease in the Young, Circulation AHA. 2002; 106(1): 143-160.

2. Williams B, Poulter NR, Brown MJ, Davis M, Mclnnes GT, Potter JF, Sever PS, McG Thom S. Guidelines for management of hypertension: report of the fourth working party of the British Hypertension Society, 2004-BHS IV. J Hum Hypertens. 2004; 18(3): 139185.

3. He FJ, MacGregor G. Blood pressure is the most important cause of death and disability in the world. Eur Heart J Suppl. 2007; 9: B23-B28.

4. World Health Organization [Internet]. The World Health Report 2002: Reducing risks, promoting healthy life. WHO, Geneva, 2002 [cited 2014 June 11]. Available from: http://www.who.int/whr/2002/en/.

5. Kearney $P M$, Whelton $M$, Reynolds $K$, Muntner $P$, Whelton PK, He J. Global burden hypertension: analysis of worldwide data. Lancet. 2005; 365(9455): 217-223.

6. Chobanian AV, Bakris GL, Black HR, Cushman WC, Green LA, Izzo JL Jr, Jones DW, Materson BJ, Oparil $S$, Wright JT Jr, et al. Seventh report of the Joint National Committee on Prevention, Detection, Evaluation, and Treatment of High Blood Pressure. JAMA. 2003; 289(19): 2560-2571.

7. Pitts SR, Adams RP. Emergency department hypertension and regression to the mean. Ann Emerg Med. 1998; 31(2): 214-218.

8. Sukor N. Secondary hypertension: a condition not to be missed. Postgrad Med J. 2011; 87(1032) : 706-713.

9. Walker, Roger; Whittlesea, Cate, editors. Clinical Pharmacy of therapeutics. 4th ed. New York: Philadelphia; 2007; pp 265-275.
10. Pierdomenico SD, Di Nicola M, Esposito AL, Di Mascio $R$, Ballone E, Lapenna $D$, Cuccurullo F. Prognostic Value of Different Indices of Blood Pressure Variability in Hypertensive Patients. Am J Hypertens. 2009; 22(8): 842-847.

11. Oppenheimer BS, Fishberg AM. Hypertensive encephalopathy. Arch Intern Med (Chic). 1928; 41(2): 264-278.

12. Kempler P. Learning from large cardiovascular clinical trials: classical cardiovascular risk factors. Diabetes Res Clin Pract. 2005; 68: S43-847.

13. Nelson-Piercy, Catherine. Handbook of Obstetric Medicine. 3rd edn. London: Informa Health Care; 2007.

14. National High Blood Pressure Education Program. Report of the National High Blood Pressure Education Program Working Group on High Blood Pressure in Pregnancy. Am J Obstet Gynecol. 2000; 183: S1S22.

15. Lowe SA, Brown MA, Dekker GA, Gatt S, McLintock CK, McMahon LP, Mangos G, Moore MP, Muller $P$, Paech $M$, Walters $B$. Guidelines for the management of hypertensive disorders of pregnancy 2008. Aust NZ J Obstet Gynaecol. 2009; 49(3): 242-246.

16. Ahmed NU, Rahman M, Islam MDU, Ali SY, Hossain AM, Fatema K, Islam MR, Sadhya G, Socio-demographic, Clinical Characteristics and Status of Hypertension Control among Rural Hypertensive Patients. Faridpur Med. Coll. J. 2011; 6(1): 05-09.

17. Rang, Humphrey P.; Dale, Maureen M.; Ritter James M.; Flower, Rod J., editors. Rang and Dale's Pharmacology. London: Churchill Livingstone; 2007; pp 410-411.

18. Das SK, Sanyal K, Basu A. Study of urban community survey in India: growing trend of high prevalence of hypertension in a developing country, Int $\mathrm{J}$ Med Sci. 2005; 2(2): 70-78.

19. Nelson, Mark. Drug treatment of elevated blood pressure. Austral Prescrib. 2010; 11(33): 108-112.

20. Bonow, Robert O.; Mann, Douglas L.; Zipes, Douglas P.; Libby, Peter, editors. Braunwald's Heart Disease: A Textbook of Cardiovascular Medicine. Philadelphia: Saunders Elsevier; 2011; pp 937-972. 